\title{
Multiple-criteria decision-making for the choice of equipment in mining using the AHP method
}

\author{
Przemysław Bodziony, Michał Patyk, Zbigniew Kasztelewicz \\ AGH University of Science and Technology, Poland
}

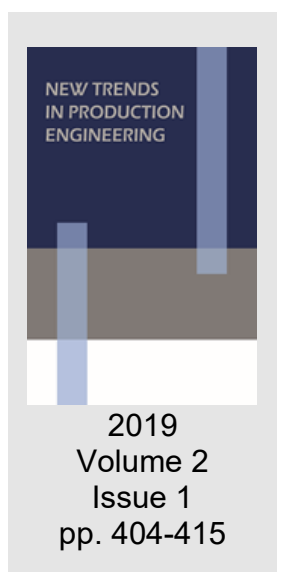

Date of submission to the Editor: 05/2019

Date of acceptance by the Editor: 08/2019

\section{INTRODUCTION}

Rational solutions for mining equipment based on the use of haul trucks, excavators, wheel loaders and crunchers should result from a thorough analysis of technical and economic issues - both cost - and operation-related - which can have a crucial impact on the cost of extracting minerals. Moreover, mining equipment should be selected in consideration of all the vital parameters in specific operating conditions and even the operator's preferences. This selection should consider hitherto disregarded criteria, such as mean availability and structure utilisation of machinery systems with the aim to improve the same (Bodziony P., et al, 2016). Considering the above issues, the following paper is an attempt at developing new and universal criteria as well as a method of evaluation and selection of means of mining equipment for mineral resource open-pit mines. The objective of this paper is to develop and implement a new methodology of multicriteria selection of mining equipment means in rock mines, based on multiple-criteria decision-making (MCDM) procedures, which will considerably contribute to the rationalisation of utilisation processes in resource use. The methodology presented in the paper illustrates the practical application of MCDM and one particular method of this type - the Analytical Hierarchy Process (AHP) - to resolve the problem in specific operational conditions of mineral resource surface mining. The applied methods facilitated the classification (ranking) of alternative solutions present in analysed systems. The proposed methodology is of a universal nature, and, consequently, it may be applied in various rock mines.

\section{SOLVING THE DECISION PROBLEM USING THE AHP METHOD}

The analytic hierarchy process (AHP) for decision problems was developed by T. Saaty. It facilitates solving multi-criteria decision problems taking into account expert analyses, which facilitates the numerical measurement of the properties of analysed elements (Saaty T. 1980, 1990). The AHP method covers a multicriteria approach based on a compensation strategy to model preferences and 
assuming variant comparability. Taking into account the preferences of the evaluator, which determine the subjectivity of comparative evaluation, is the core of the multi-criteria approach, which treats such preferences as natural for manmade judgments. Decision problem analysis using the AHP method can be divided into two phases:

Developing a hierarchical representation of the problem. At the top of the hierarchy there is the primary objective, while the considered decision alternatives are found at the bottom. At the intermediate levels, there are the considered constituents of the problem, such as the decision criteria or other factors which influence progress on the primary objective and the selection of the most favourable alternative.

AHP-based analysis is carried out in four steps:

- Stage 1 - building and arranging the hierarchical model - presenting the problem, determining alternative judgment criteria

- Stage 2 - evaluating the validity of the criteria, sub-criteria and decision alternatives through pairwise comparison;

- Stage 3 - determining joint priorities (significance) in respect of the criteria and decision alternatives. Verifying the correctness of the results (testing matrix coherence);

- Stage 4 - synthesising the order of preferable alternatives obtained from a standardised judgment matrix (classifying decision alternatives).

In order to determine priority vectors for the criteria and alternatives, the following relationships were applied:

$$
\begin{gathered}
a_{i}^{*}=\sqrt[n]{\prod_{j=1}^{n} a_{i j}}, i=\overline{1, n} \\
a^{*}=\sum_{i=1}^{n} a_{i}^{*} \\
w_{i}=\frac{a_{i}^{*}}{a^{*}} ; \quad i=\overline{1, n}
\end{gathered}
$$$$
A=\left[\begin{array}{ccccc}
a_{11} & \cdots & a_{1 j} & \cdots & a_{1 n} \\
\vdots & \ddots & \vdots & & \vdots \\
a_{i 1} & \cdots & a_{i j} & \cdots & a_{i n} \\
\vdots & & \vdots & \ddots & \vdots \\
a_{n 1} & \cdots & a_{n j} & \cdots & a_{n n}
\end{array}\right]
$$

where:

$\mathrm{w}_{\mathrm{i}}$ - the coefficients of dominance between factors,

$a^{*}$ - absolute rank of criterion $a_{i}$

$a^{*}{ }_{i}$ - absolute rank of criterion $a_{i j}$, with $a_{i j} \in\{1,2,3, \ldots, 9\}$

The highest eigenvalue of the comparison matrix is determined by the following relationship:

$$
\lambda_{\text {max }}=\sum_{j=1}^{n} a_{j}^{*} w_{j}
$$

where:

$\lambda_{\max }$ - maximum eigenvalue of $\mathrm{n}$-th order comparison matrix,

For consistency evaluation, a consistency index was defined using the following formula:

$$
\text { C.I. }=\frac{\lambda_{\max }-n}{n-1}
$$


Consistency ratio was calculated using the formula:

$$
\text { C.R. }=\frac{\text { C.I. }}{\text { R.I. }}
$$

The R.I. is a constant and depends on the matrix dimension (Saaty T. 1980, 1990).

\section{ANALYSIS OF EVALUATION AND DECISION MAKING FOR THE SELECTION OF EQUIPMENT IN SURFACE MINING WITH THE APPLICATION OF THE AHP METHOD}

When building the family of criteria and selecting the set of alternatives, and taking into account the selection of the ranking method and the implementation of decision-makers' preference models, the following aspects were taken into consideration:

- determining the purpose of the analysis,

- determining the set of permissible and comparable alternatives (configurations of process systems) to be judged and their characteristics,

- determining the set of evaluation criteria for the alternatives,

- determining the decision rules for alternative handling,

- defining criteria preferences,

- defining alternative preferences for given criteria,

- determining the value characteristic of a given alternative,

- determining the value of the indicator characterising preference judgment consistency, when the required consistency was not reached,

- adjusting preference judgments (revaluating preferences).

\section{DESIGNING OF DECISION ALTERNATIVES - A PROCESS-LINE CONFIGURATION FOR LOW-QUALITY ROCK DEPOSITS}

As a result of karstic formations, $20 \%$ of the studied limestone seam comprises ungraded material (waste stone) which is unfit for use further in the process. In our study, we used the term seam quality 80 , meaning that intermediate product comprises $80 \%$ of the seam, and assuming that the rock extracted from the bed should be preliminarily crushed to remove the karst fraction, with a particular size distribution of $0-40 \mathrm{~mm}$, from the final material. The fraction that is fit for use further in the process (intermediate product) has a particular size distribution of more than $40 \mathrm{~mm}$. Three possible process-line configurations were proposed to select the best alternative for the seam conditions under study. In each mining system, the extracted rock was loaded on a mobile crusher with a backhoe; a wheel loader was used to load haul trucks; rigid-frame haul trucks with a capacity of $55 \mathrm{Mg}$ were used to transport the extracted rock to the waste rock dump for preliminary crushing of ungraded material, and to transport intermediate product to the processing plant. The location of preliminary crushing is different for each of the mining systems compared (Fig. 1) (Patyk M., Bodziony P., 2018). 


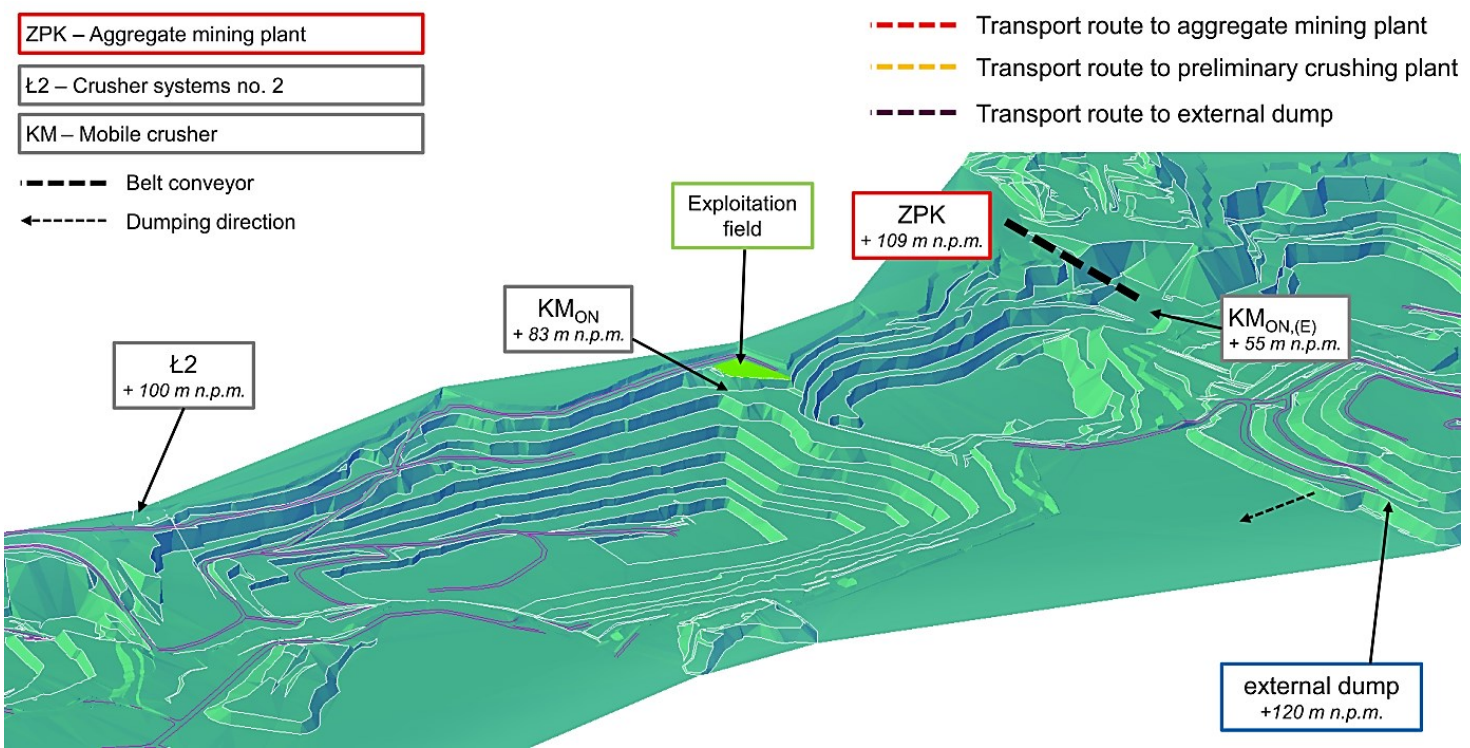

Fig. 1 Preliminary crushing locations in the analysed mine

The set of alternatives to be covered by the analysis was defined in advance and was not subject to change during the decision-making process based on the existing machine stock.

Alternative $\mathbf{A} 1$ is the only alternative in which preliminary crushing takes place near the face, with the shortest transport routes and the lowest number of mining system components.

Alternative $\mathbf{A} 2$ is the only alternative in which intermediate product is transported from the mobile crusher to the processing plant via a belt conveyor, with a medium length of haulage roads.

Alternative A3 involves preliminary crushing of material in a stationary crusher, with the longest transport routes, and the optimum proportion of intermediate product in the seam. In this system, the extracted rock is crushed by two crusher systems to yield $2 \%$ more intermediate product than the other alternatives. A more compound crushing system ensures increased exploitation of the seam and reduces overburden.

\section{UNIVERSAL CRITERIA FOR THE EVALUATION AND SELECTION OF MINING EQUIPMENT IN ROCK MINING}

For the purposes of a complementary analysis of a decision problem, a coherent family of criteria was specified, taking into account reliability, technological, and economic aspects:

K1 Mean failure intensity

K2 Reliability index indicator $K_{g t}$

K3 Mean Time Between Failures

K4 Mean Time To Restoration

K5 Machine stock size

K6 Energy-consumption of the mining equipment

K7 Total operating costs

K8 Total investment costs 
K9 Process-related costs.

K1 Mean failure intensity - is a minimised criterion characterising the number of machine exclusions in the operating system due to failure. The failure intensity can be estimated on the basis of statistical studies as the parameter describing an empirical number of mining equipment exclusions (failure intensity) from the operating system use due to failures. This parameter makes it possible to determine a mean number of maintenance requests for the same machine to the restoration system, neglecting the restoration time. The mean failure intensity was determined as the mean value of exclusions for the analysed mining equipment population, falling to the entire range of analysed operation time (14.000 mth) acc. to relationship (5) (Hebda M., 2005). This parameter's value is expressed as [failure/mth].

$$
\Delta_{i}=\frac{\Delta n_{i}}{N_{o} \cdot L_{p}}
$$

$\Delta n_{i}-$ the number of registered damages in the $i$-th range of the analysed duty [damages],

$N_{o}$ - the number of specific type of machines in the analyzed population [units], $L_{p}-$ the total length of the range of the analyzed duty (14.000 engine hours).

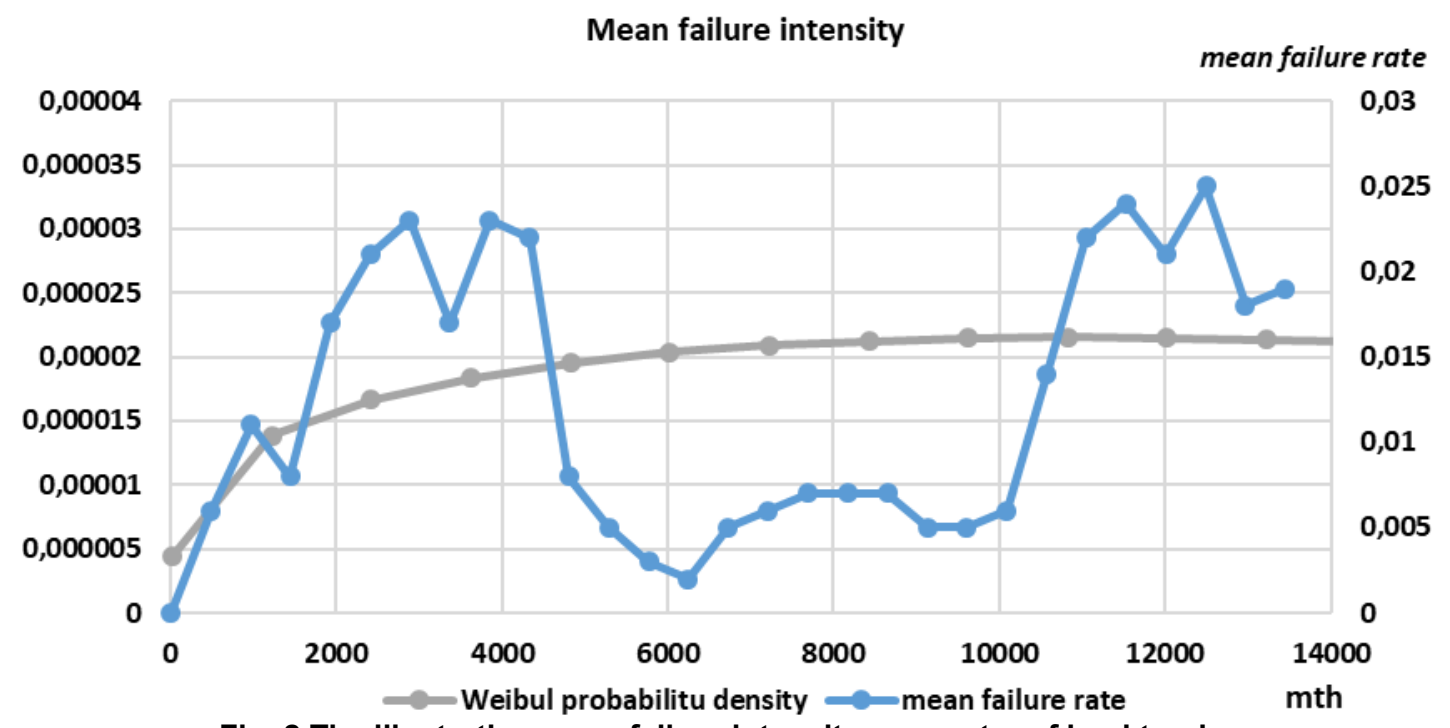

Fig. 2 The illustrative mean failure intensity parameter of haul trucks, for the total observation period of 14,000 hours of operation

K2 Reliability index indicator $\boldsymbol{K}_{\mathbf{g t}}$ - a maximised reliability criterion that defines the probability that a machine is functional and works at any given time. This criterion is determined as the quotient of all Reliability index indicators for the considered types of machinery that make up the mining machine system, as a mean value for each type of machine (transportation, loading and processing machines). The value of this criterion is expressed in [\%].

$$
K_{g t}=\frac{\sum_{i=1}^{n} t_{i}^{(j)}}{\sum_{i=1}^{n} t_{i}^{(j)}+\sum_{i=1}^{n} t_{i}^{\left({ }^{(n)}\right.}}
$$

where:

$t_{i}^{(j)}$ - machine's effective operating time in $i$-th day of operation [h], 
$t_{i}^{(n)}$ - total repair and maintenance time, including:

$t_{r}$ - effective repair downtime [h],

$t_{s}$ - time of repair by an external repair service [h],

$t_{p w}-$ workshop downtime (awaiting repair) [h].

K3 The MTBF (mean time between failures) index - a maximised reliability criterion which illustrates how frequently, from statistical point of view, a specific technical object is damaged. In practice, this index can be helpful to determine the schedule of planned preventive inspections.

The MTBF index was adopted as a mean operating time between failures within a specified time. This index is calculated acc. to:

$$
\begin{gathered}
M T B F=\frac{\text { number of failures } \times \text { number of up time }}{\text { number of failures during the test }} \\
=\frac{T_{1}+T_{2}+T_{3} \ldots+T_{n-1}+T_{n}}{n}
\end{gathered}
$$

Therefore, the MTBF is a mean expected time between consecutive failures of a specific object, assuming that it is subject to alternating periods of failures and repairs. The following relationship defines MTBF as an inverse of failure occurrence frequency $\lambda(t)$ (Gulati R, Smith R., 2009).

This index value depends on the mining equipment use intensity and on the conditions, under which it is operated. It is also required to determine the profile of use, i.e. the operational conditions and the operating time (14.000 mth). For machines system and their sub-assemblies, the operating hours should be additionally provided considering the specific nature of operation (type of transport roads, time of operation under load, time of idle operation etc.).

K4 The MTTR (mean time to restoration) index - a minimised reliability criterion which determines a mean time necessary to remove the failure. It is also used to evaluate the effectiveness of the repair service (external) and of own maintenance services, and also to assess the repair jobs carried out by them.

The MTTR index was adopted as a mean time of actual repair duration from the moment of request to the moment of its completion. It is calculated according to the relationship:

$$
\begin{gathered}
M T T R=\frac{\text { internal sum of repair time }}{\text { number of failures during the test }} \\
=\frac{t_{1}+t_{2}+t_{3} \ldots+t_{n-1}+t_{n}}{n}
\end{gathered}
$$

The MTTR is a mean value of the time period, in which mining equipment is in the down time due to a failure. The MTTR is also defined as the mean down time (MDT). It comprises the time of failure detection, its recognition and identification, request serving, ordering to the restoration system, which should remove the failure, time of its removal and the operating test (Gulati $R$, Smith R., 2009). 
Mean MTBF and MTTR values for various configuration of the machine stock comprising the analysed process system were adopted for analysis.

K5 Machine stock size - a minimised quantitative criterion related to technology that defines the total number of machines that make up the machinery stock (decision alternative), expressed in [pcs.]. The amount of mining equipment depends on the configuration of process variants and, in the case of transportation fleet, on the length of hauling routes and the efficiency of the transport equipment, as shown in Table 1.

Table 1 Number of machines by variant

\begin{tabular}{|l|c|c|c|c|}
\hline \multicolumn{1}{c|}{ Variant } & Unit & A1 & A2 & A3 \\
\hline Machine type & pcs. & 3 & 3 & 5 \\
\hline Haul trucks & pcs. & 1 & 1 & - \\
\hline Excavator & pcs. & 1 & 2 & 2 \\
\hline Mobile crusher (diesel) & pcs. & 1 & - & - \\
\hline Mobile crusher (electrical) & pcs. & - & 1 & - \\
\hline Stationary crusher & pcs. & - & - & 1 \\
\hline Grading screen & pcs. & - & - & - \\
\hline Belt conveyor & pcs. & - & 1 & - \\
\hline Total & pcs. & $\mathbf{6}$ & $\mathbf{8}$ & $\mathbf{8}$ \\
\hline
\end{tabular}

K6 Energy-consumption of the mining equipment - a minimised qualitative criterion related to the environment that defines the total use of energy by the mining equipment that makes up a mining machine system. This criterion describes which of the mining machine systems represent the lowest degree of environmental nuisance due to carbon dioxide emissions - i.e. which of the systems are characterised by the lowest energy consumption and $\mathrm{CO}_{2}$ emissions over two work shifts. This criterion is expressed in [MJ/day].

K7 Total operating costs - is a minimised criterion, aggregating all relevant components of the operating cost, assigned to the various technological means of mining equipment. It includes the major components of operating costs, such as: fuel costs, tires, fluids, maintenance and technical services, and repair (including the purchase of services and own work), excluding spare parts. Components of the operating costs also include leasing costs, operators' and supervisors' salaries, insurance and transport taxes, depreciation, and other administrative fees. This criterion is expressed in monetary units [PLN].

K8 Total investment costs - a minimised formula, aggregating all relevant components of the investment costs, related to the present, in real terms or capitalised at the date of the analysis. The criterion includes all cost components that are related to investments in mining equipment (haul trucks, wheel loader, excavators and processing machines, preparation of operating facilities, roads, loading and unloading points, etc). This criterion is expressed in monetary units [PLN] . 
K9 Process-related costs - a minimised quantitative economic criterion related to the aggregate of all significant process-related costs of obtaining intermediate product and ungraded material, i.e. all the cost items generated by the mining machine system in a working day, expressed in [PLN/day].

\section{THE SELECTION OF EQUIPMENT IN SURFACE MINING WITH THE APPLICATION OF THE AHP METHOD}

In order to analyse the MCDM problem using the AHP method, a decision matrix was created, which covered the values of the criteria for the adopted decision alternatives (Table 2). Next, decision rules for alternative handling were determined.

Table 2 Decision matrix with the values of the criteria for the adopted decision alternatives

\begin{tabular}{|c|c|c|c|c|c|c|c|c|c|c|}
\hline & $\begin{array}{c}\text { Specific- } \\
\text { ation }\end{array}$ & K1 & K2 & K3 & K4 & K5 & K6 & K7 & K8 & K9 \\
\hline \multirow{3}{*}{ 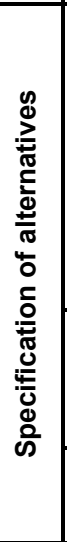 } & 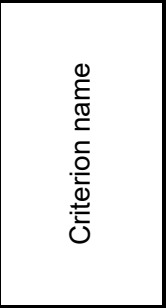 & 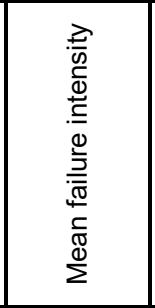 & 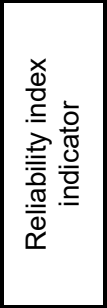 & 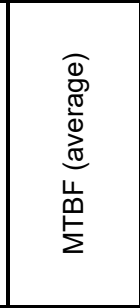 & 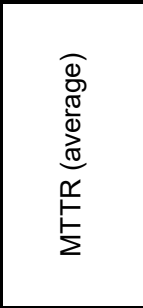 & 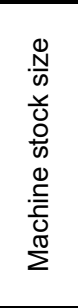 & 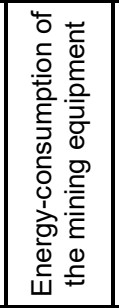 & 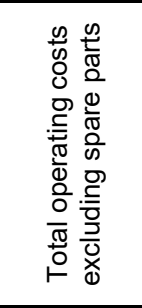 & 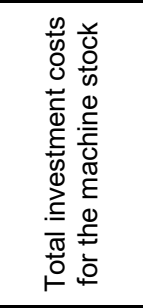 & 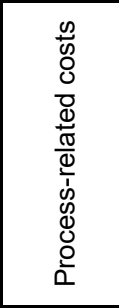 \\
\hline & Unit & $\begin{array}{c}1 \text { thousand } \\
\text { mth }\end{array}$ & [\%] & $\begin{array}{c}14 \\
\text { thousand } \\
\text { mth }\end{array}$ & $\begin{array}{c}14 \\
\text { thousand } \\
\text { mth }\end{array}$ & Pcs. & MJ] & PLN/year & $\begin{array}{c}\text { PLN } \\
\text { thousand }\end{array}$ & $\begin{array}{l}\text { PLN/Mg } \\
\text { of semi- } \\
\text { finished } \\
\text { product }\end{array}$ \\
\hline & $\begin{array}{l}\text { Direction of } \\
\text { preference }\end{array}$ & $\min$ & $\max$ & $\max$ & $\min$ & $\min$ & $\min$ & $\min$ & $\min$ & $\min$ \\
\hline & W1 & 0,9385 & $93,1 \%$ & 491,75 & 3,92 & 6 & 103194 & 568515 & 11395 & 3,97 \\
\hline & W2 & 0,774 & $94,0 \%$ & 503,78 & 3,64 & 8 & 125925 & 716538 & 13443 & 5,04 \\
\hline & w3 & 1,2483 & $93,6 \%$ & 327,90 & 4,4 & 8 & 170885 & 990326 & 12900 & 6,79 \\
\hline
\end{tabular}

Figure 4 compares the determined values of alternative preferences by criterion.

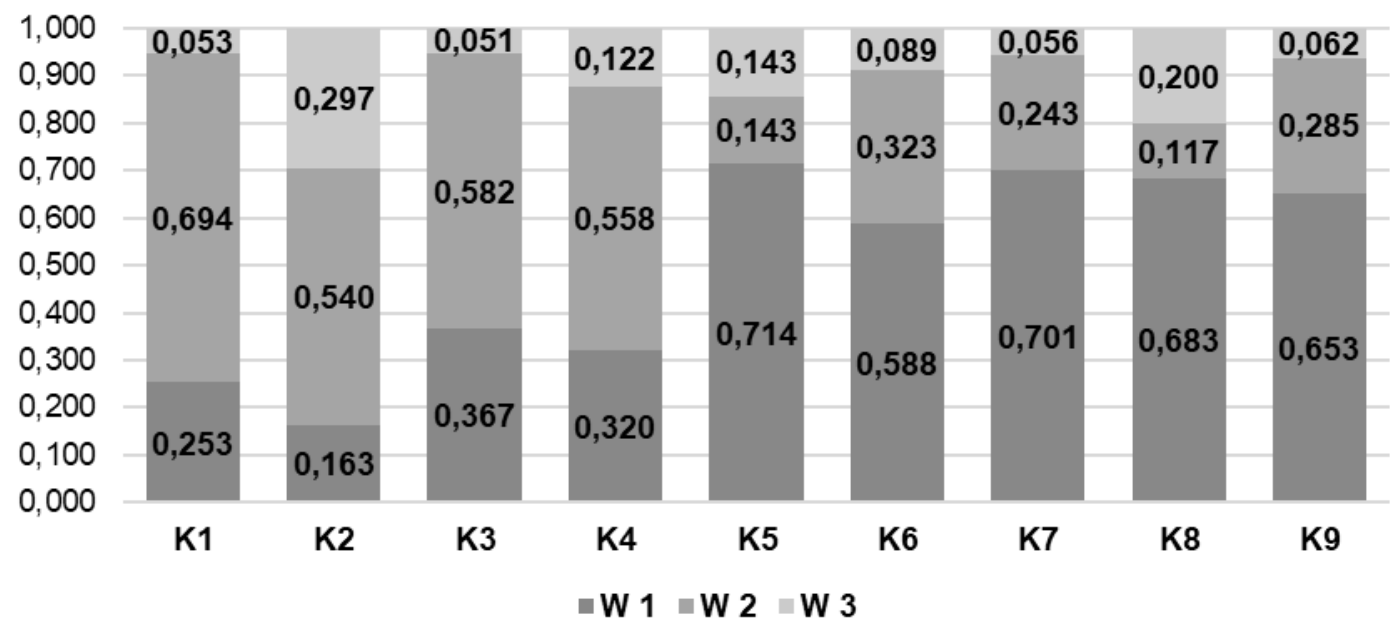

Fig. 4 The preference values for each criterion (judging the usefulness of decision alternatives)

The individual alternatives are colour-coded, and their level of significance is represented by the field size. 
Alternative $A 3$ is characterised by the lowest significance when compared with the other decision alternatives - the mean significance is 0.119 . Alternative $A 2$ is the most significant alternative in criteria from $\mathrm{K} 1$ to $\mathrm{K} 4$, while alternative $\mathrm{A} 1$ in criteria from $\mathrm{K} 5$ to $\mathrm{K} 9$. The mean significance level of alternative $\mathrm{A} 1$ is 0.494 , while of alternative $\mathrm{W} 2$ equals 0.387 .

In order to evaluate and select the most favourable of the process systems, indepth interviews with three experts were carried out. Each of the experts determined the relative significance of the devised criteria, his/her own preferences as regards the criteria, and determined alternative preferences by criterion. As part of the analysis, the group of decision makers was a selected, independent team of experts, and they were presented with the decision matrix with values of the criteria for the adopted alternatives (Table 3 and Fig. 5).

Table 3 The significance levels depending on comparative evaluation made by individual experts

\begin{tabular}{|ll|c|c|c|}
\hline \multicolumn{2}{|c|}{ Criterion } & \multicolumn{3}{c|}{ Significance } \\
\cline { 3 - 5 } & E1 & E2 & E3 \\
\hline K1 & Mean failure intensity (14 thousand mth) & 0.099 & 0.059 & 0.069 \\
\hline K2 & Reliability index indicator Kgt & 0.090 & 0.104 & 0.111 \\
\hline K3 & Mean Time Between Failures & 0.021 & 0.046 & 0.089 \\
\hline K4 & Mean Time To Restoration & 0.061 & 0.077 & 0.035 \\
\hline K5 & Machine stock size & 0.028 & 0.086 & 0.018 \\
\hline K6 & Energy-consumption of the mining equipment & 0.191 & 0.079 & 0.162 \\
\hline K7 & Total operating costs & 0.382 & 0.213 & 0.212 \\
\hline K8 & Total investment costs & 0.045 & 0.033 & 0.049 \\
\hline K9 & Process-related costs & 0.084 & 0.304 & 0.256 \\
\hline
\end{tabular}

Expert 1

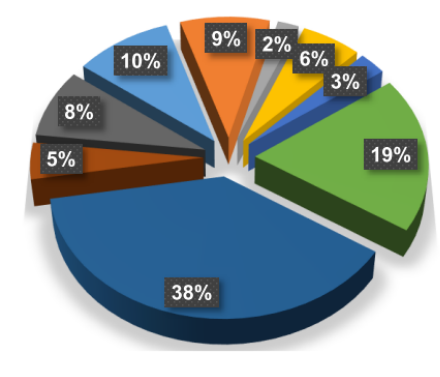

-K1 Mean failure intensity for 12 thousand/month $=\mathrm{K} 4 \mathrm{MTTR}$ (average)

- K7 Total operating costs excluding spare parts
Expert 2

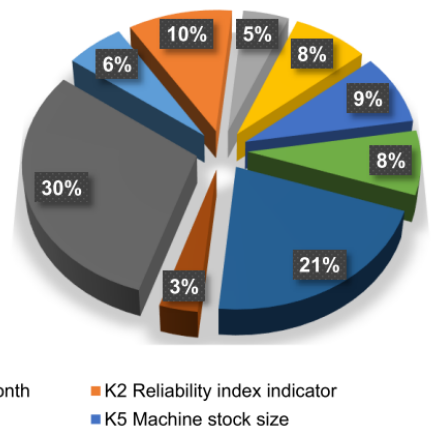

Expert 3

Fig. 5 The percentage distribution of the weights

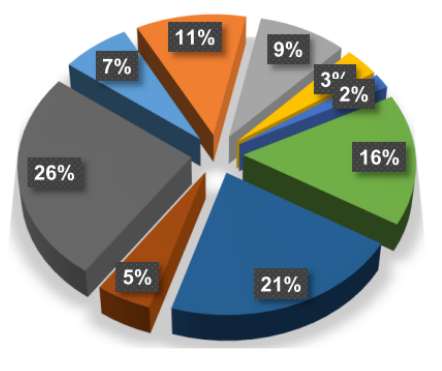

$=$ K3 MTBF (average)

-K6 Energy consumption of the mining equipment K9 Process-related costs

of individual criteria according to expert's preferences

The team was composed of three academics-experts, two of whom had managerial experience in mining. The first expert works in the field of analysing the operation and reliability of machines process systems, as well as modelling decision-making processes. The second expert specialises in analysing the operation of engineering machines and their selection in open-pit mining, in particular of minerals. The focus of the third expert lies in analysing open-pit mining technology and planning and managing the maintenance of mining facilities. Each of the experts determined the relative significance of the devised criteria and their own preferences (Table 3). 
Figure 5 presents the percentage distribution of the significance of individual criteria depending on the experts' preferences and comparative evaluation. According to expert E1, the most important criterion is criterion $\mathrm{K} 7$ (total operating costs), accounting for $38 \%$ of the significance of all criteria.

Other important criteria, as proposed by this expert, are criterion K6 (Energyconsumption of the mining equipment) $-19 \%$ and $\mathrm{K} 1$ (Mean failure intensity) 10\%. Experts E2 and E3 regarded criterion K9 (Process-related costs) as the most important $(30 \%$ and $26 \%$, respectively) with criterion $\mathrm{K} 7$ (total operating costs) as the second in terms of importance (21\% each). In expert E2's opinion, the third most significant criterion is criterion K2 (Reliability index indicator) $10 \%$, while according to expert E3, it is criterion K6 (Energy-consumption of the mining equipment) $-16 \%$. All experts ranked criterion K8 (Total investment costs) among the least important criteria, with its significance within the range of $3-5 \%$.

The expert specializes in machine operating focused on two fields of criteria. The first one covered technical and reliability parameters, placing emphasis on indicators which describe energy-intensity consuption and failure rate. The other field, crucial for this expert, was economic criteria encompassing primarily the operating costs of the machine stock. The experts in the engineering aspects in open-pit mining displayed similar standpoints as regards the adopted criteria. They regarded process-related costs as a criterion with the highest relative significance. Furthermore, operating costs were also important.

It is worth highlighting that the cost criteria constituted a universally significant parameter for all expert circles. Through the application of a calculation procedure in the AHP method, three expert rankings were individually generated for each of the adopted decision-maker's preference models. Next, a final ranking was drawn up. The final order presented in Figure 6 indicates that, as regards the adopted decision-makers' preference models, Alternative 1 is superior to the other ones, constituting the most favourable solution - it is preferred in $54.7 \%$ on average. Next is Alternative A2 preferred in $35.4 \%$. The least favourable is Alternative A3 with a preference of $10 \%$.

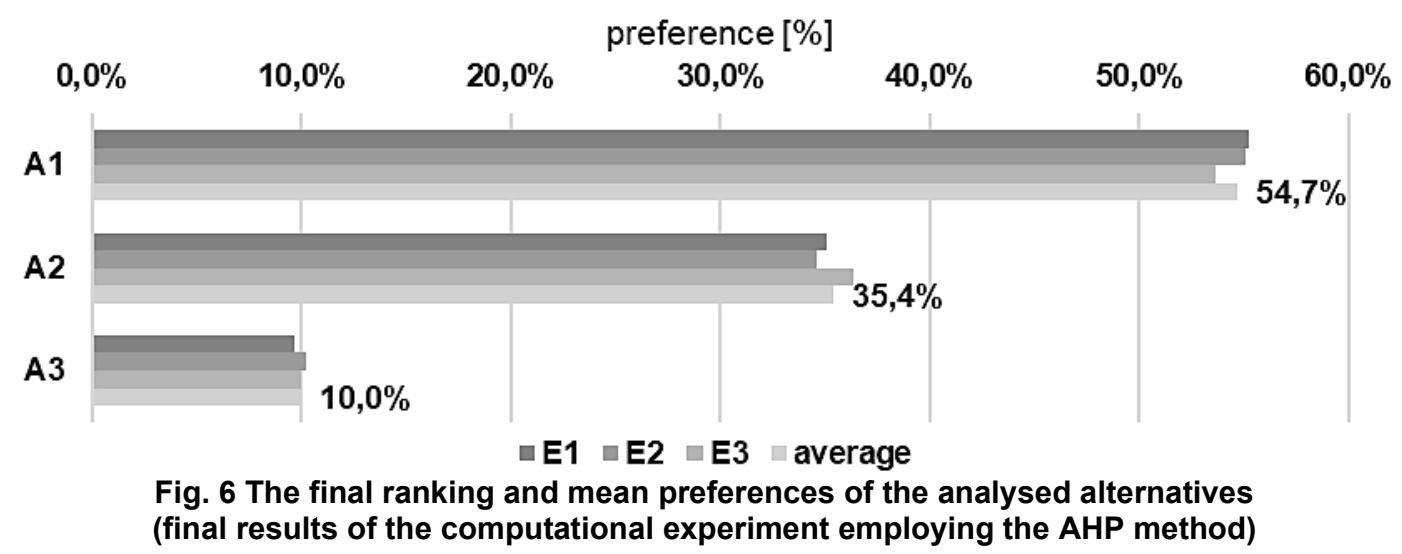

The obtained results of all analyses clearly indicate the superiority of Alternative A1. This alternative meets all the major criteria accentuated by experts in open- 
pit mining engineering and machine operation. Furthermore, this alternative scores highly in terms of the criterion regarded by all decision-makers as the most significant, i.e. operating costs.

\section{CONCLUSIONS}

The presented methodology illustrates the practical application of multiplecriteria decision-making (MCDM) and AHP, which is one of the methods used in this trend, to solve the problem of evaluation and selection of process machinery in the specific operating conditions of open-pit mines. The presented example showcases an undeniable advantage of AHP - the necessity to select a solution when there is a conflict of interests among decision-makers. It is particularly important to apply the method to establish preferences in respect of criteria in the form of relative weights which reflect the importance of the criteria in the final evaluation.

The proposed methodology is universal and can be used in many mining facilities, especially in the case of evaluating and selecting the machinery stock. It is noteworthy that this universal character is influenced by:

- devising (specifying) a set of reliable criteria allowing comprehensive and multifaceted analysis,

- conducting a complex process of modelling and aggregating interdisciplinary decision criteria to reliably evaluate their value and appropriately define their nature and scopes;

- conducting an analysis of the preferences of decision-makers from various expert backgrounds,

- introducing simplifications in the modelling of the actual situation, which, however, provides practical benefits in the form of a simplified procedure in the decision-support process.

\section{ACKNOWLEDGEMENTS}

The article was implemented as part of statutory subsidy No. 16.16.100.215.

\section{REFERENCES}

Bodziony P., Kasztelewicz, Z., Sawicki, P. (2016). The Problem of Multiple Criteria Selection of the Surface Mining Haul Trucks (Archives of Mining Sciences 2016), no. 61 pp. 223-243.

Gulati, R., Smith, R. (2009). Maintenance and Reliability Best Practices. [Electronic] New York: Industrial Press.

Hebda M., (2005). Eksploatacja samochodów, Instytut Technologi i Eksploatacji Panstwowy Instytut Badawczy, Radom.

Patyk, M.,Bodziony, P. (2018). Analysis of multiple criteria selection and application of APEKS method in haul truck mining transport process, E3S Web of Conferences, vol. 71 no. 00003, s. 1-6, XVIII Conference of PhD Students and Young Scientists "Interdisciplinary Topics in Mining and Geology", Szklarska Poręba, Poland, May 22-25, 2018;

Saaty, T. (1980). The Analytic Hierarchy Process, McGraw-Hill, New York.

Saaty, T. (1990). How to Make a Decision: The Analytic Hierarchy Process, European Journal of Operational Research 1990, vol. 48, pp. 9-26. 


\begin{abstract}
.
Rational solution for mining equipment based on the use of haul trucks, excavators, wheel loaders and crunchers should result from thorough analysis of technical and economic issues - both cost-related and exploitational - which can have a crucial impact on the cost of minerals extraction. Moreover mining equipment should be selected with consideration for all vital parameters in specific exploitational conditions and even the exploiter's preferences. This selection should consider hitherto disregarded criteria, such as mean availability and structure utilization of machinery systems with the aim to improve the same. Methodology presented in the paper illustrates practical application of MCDM and one particular method of this type the Analytical Hierarchy Process (AHP) - for resolving the problem in specific exploitational conditions of mineral resource in surface mining AHP method covers a multi-criteria approach based on a compensation strategy to model preferences and assuming variant comparability. Taking into account the preferences of the evaluator, which determine the subjectivity of comparative evaluation, is the core of the multi-criteria approach, which treats such preferences Considering the above issues, the following paper is an attempt to develop new and universal criteria as well as a method of evaluation and selection of means of mining equipment for mineral resource surface mines.
\end{abstract}

Keywords: surface mining, mining equipment, utilisation, reliability parameters, Multiplecriteria decision-making (MCDM), AHP 